\title{
Dangerous Gas Detection using an Integrated Circuit and MQ-9
}

\author{
Falohun A.S. \\ Dept. of Computer Sc. \& Eng. \\ Ladoke Akintola Univ. of Tech.
}

\author{
Oke A.O. \\ Dept. of Computer Sc. \& Eng. \\ Ladoke Akintola Univ.of Tech.
}

\author{
Abolaji B.M., Oladejo \\ O.E. \\ Dept. of Computer Sc. \& Eng. \\ Ladoke Akintola Univ.of Tech.
}

\begin{abstract}
Natural gas is an odourless one which consists of compounds made of two elements: carbon and hydrogen called hydrocarbons. Sometimes, due to an accident or if the valve is not properly closed, the gas leaks. This system is aimed at detecting the leakage and sounding an alert so that occupants in the building can maintain optimal ventilation and turn off all electrical appliances or evacuate the vicinity until a redress is made.
\end{abstract}

An MQ-9 chemical sensor coupled with an Integrated Circuit was used to build the system and on testing, the system gave adequate visual information, audible and timely alert on detecting a gas leakage.

\section{General Terms}

Security, Safety, Signal, Gas, Casing.

\section{Keywords}

Sensor, Buzzer, Embedded, Soldering, Alarm.

\section{INTRODUCTION}

In this fast developing society, electronics has come to stay as the most important branch of Engineering. Electronic devices are being used in almost all industries for quality control and automation and they are fast replacing the present vast army of workers engaged in processing and assembling in the factories. These devices supplement the human ability to sense, monitor, calculate, observe, and control. [8]

An uncontrolled combination of fuel with oxygen releases heat and any unintended contact with a spark can cause burning. Automatic gas detecting systems are intended to notify the building occupants to evacuate in the event of the gas leakage or other emergency, report the event to an offpremises location in order to summon emergency services, and to prepare the structure and associated systems to control the spread of gas and fire. [3]

This work is about the design and construction of a gas detector with audible alarm. This gas detector with audible alarm is designed with the intention to ensure that the event of gas is intelligently detected, promptly notified and interactively managed than what is obtainable with conventional "ring-ring" fire alarm systems.

'Jet Age' is what the age is called as the growing desire of human, is that things are done in the twinkle of an eye (i.e. food get cooked in a minute, uninterrupted power supply, fast transportation of people and loads, fast access to knowledge base (Internet), Internet banking, social media communication, online classes). And these have led to breathtaking inventions to cater for these desires. One of such is the gas-cooker, whose work is of great benefit. It is observed that the destruction caused by fire due to gas leakage is quite alarming and building occupants are slow in responding to alarm systems. Dr. Guylène Proulx in [6] discussed three reasons why occupants may ignore the alarm signal as:

- Failure to recognize the signal as a fire alarm.

- Loss of confidence in the system because of nuisance alarms, or,

- Failure to hear the signal if there is other source of sound apart from the alarm system or the resident is partly with deafness disability.

Therefore, a gas detector with audible/visual alarm presented herein tends to solve these identified problems through the design and construction of a low-cost, easy to construct gas detection system via gas sensor. Figure 1 gave a hint on the alarm system built around a Timer which is easy to work with, affordable and easy to design and construct, instead of a Microcontroller.

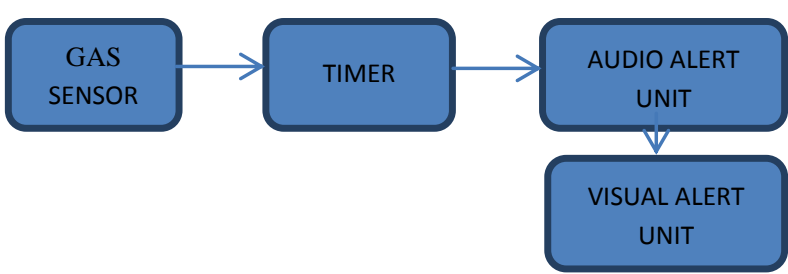

Figure 1: Block diagram of the user-interactive fire alarm system.

\section{LITERATURE REVIEW}

\subsection{Gas Alarm Systems}

An automatic gas alarm system is designed to detect the unwanted presence of fire by monitoring environmental changes associated with combustion. [2]

In general, a fire alarm system is classified as either automatically actuated, manually actuated, or both. [5]. Automatic fire alarm systems are intended to notify the building occupants to evacuate in the event of a fire or other emergency, report the event to an off-premises location in order to summon emergency services, and to prepare the structure and associated systems to control the spread of fire.

\subsection{Parts of a Fire Alarm System}

Primary Power supply: Commonly the non-switched 120 or 240 Volt Alternating Current source supplied from a commercial power utility. In non-residential applications, a branch circuit is dedicated to the fire alarm system and its constituents. "Dedicated branch circuits" should not be confused with "Individual branch circuits" which supply energy to a single appliance.

Secondary (backup) Power supplies: This component, commonly consisting of sealed lead-acid storage batteries or other emergency sources including generators, is used to supply energy in the event of a primary power failure. 
Initiating Devices: This component acts as an input to the fire alarm control unit and are either manually or automatically actuated. Examples would be devices pull stations, heat detectors, or gas detectors. Heat and gas detectors have different categories of both kinds. Some categories are beam, photoelectrical, aspiration, and duct.

Notification appliances: This component uses energy supplied from the fire alarm system or other stored energy source, to inform the proximate persons of the need to take action, usually to evacuate. This is done by means of a flashing light, strobe light, electromechanical horn, "beeper horn", chime, bell, speaker, or a combination of these devices.

Building Safety Interfaces: This interface allows the fire alarm system to control aspects of the built environment and to prepare the building for fire, and to control the spread of gas fumes and fire by influencing air movement, lighting, process control, human transport and exit. [13]

Microcontrollers are designed for small or dedicated applications. Microcontrollers are used in automatically controlled products and devices, such as automobile engine control systems, implantable medical devices, remote controls, office machines, appliances, power tools, and toys. By reducing the size and cost compared to a design that uses a separate microprocessor, memory, and input/output devices, microcontrollers make it economical to digitally control even more devices and processes. Mixed signal microcontrollers are common, integrating analog components needed to control non-digital electronic systems. [14]

\subsection{Embedded Design}

A microcontroller can be considered a self-contained system with a processor, memory and peripherals and can be used with an embedded system. (Only the software needs be added). The majority of microcontrollers in use today are embedded in other machinery, such as automobiles, telephones, appliances, and peripherals for computer systems. These are called embedded systems. While some embedded systems are very sophisticated, many have minimal requirements for memory and program length, with no operating system, and low software complexity. Typical input and output devices include switches, relays, solenoids, LEDs, small or custom LCD displays, radio frequency devices, and sensors for data such as temperature, humidity, light level etc. [6] .Embedded systems usually have no keyboard, screen, disks, printers, or other recognizable I/O devices of a personal computer, and may lack human interaction device. [1] .The amount and type of detectors and the type of fire alarm system that one chooses for property protection will depend on the owner's property protection goals, the value of the property and the requirements of the owner's insurance company.

Generally, heat detection will be used in all areas that are not considered high value. Here again, one of the most common mistakes in fire alarm system application is to provide partial protection of a building and expect high performance from the installed systems of any kind . [5]

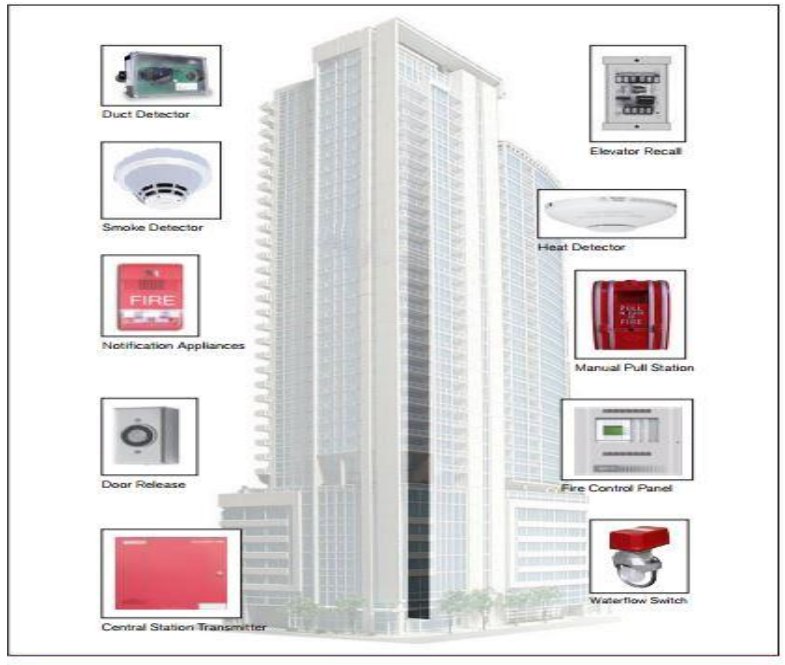

Figure 2: A typical Fire Alarm System (Source: [1])

\subsection{Review of Related Works}

[15] developed a system to counter the problems of gas accidents in coal mines and family safety from gas usage through the use of a new infrared detection optics principle. The infrared optics gas detection was high in detection accuracy, long range service life. It the system allowed the passage of infrared signal to the gas intended for measurement while its molecules will absorb the light energy. The absorption relationship followed Lamber-Beer law.

In the year 2014, [12] stated that an efficient and smooth working controller is needed to continuously sense both leakage and level of the gas. And also fast response is required when leakage is found and the monitoring system must provide additional leakage information which can be used in further processing. The detection system includes Arduino duemilanove, microcontroller board compatible with ATmega328p. coupled with the system is the weight sensor, LCD display, GSM and DC motor.

[4] designed and implemented a GSM-Based Remote Monitoring System. The paper focused on wireless monitoring because the wireless remote monitoring system has a wider application. The hardware and software architecture of the system was designed where the remote signal is transmitted through GSM network. The system has two parts: the monitoring center and the remote monitoring station. The monitoring center consists of a computer and a TC35 communication module for GSM. The computer and the TC35 are connected by RS232. The remote monitoring station consist of a TC35 communication module for GSM, an MSP430F149 MCU, a display unit, sensors and a data gathering and processing unit. The software for the monitoring center and the remote monitoring station were designed using VB.

A review of gas leak detection techniques was done by [9] with a classification of leak detection methods in a gas pipeline to monitor the integrity of a pipeline.

In terms of mode of operation, [12] settled for the use an Arduino board, which is quite expensive and bulky. [10] used microcontroller (PIC16F877), which in turn is a soft real time system. It is said that "A hard real time system should always respond to an event within the deadline or else the system fails and endangers human lives but in soft real time system, 
failing to meet the deadline produces false output and does endanger the human lives."

\section{DESIGN ANALYSIS}

\subsection{Circuit Diagram}

The schematic diagram in Figures $3 \mathrm{a}$ and $3 \mathrm{~b}$ diagrammatically depicts the gas detection system (i.e. from the power stage, detection and alarm stage).

The amount of supplied power into the circuit is dependent on the combined power usage on each component in the circuit. From the right-most part of Figure 3 is written $12 \mathrm{~V}, 300 \mathrm{~mA}$ i.e. the calculated average power that was sufficient to power the whole circuit. And this power was generated from an ACDC adapter which can step down, rectify and stabilize outputs.

The adapter gets connected to the circuit board via a polarized adapter jack port which is not fixed on the board but screwed to the casing that houses the whole circuit. From the supplied $12 \mathrm{~V}, 300 \mathrm{~mA}$, is connected the U1, 78L05 a three (3) pin voltage regulator which is supplied with any DC $<35 \mathrm{~V}$ and will always give the DC output of $5 \mathrm{~V}$.

This DC output of $5 \mathrm{~V}$ is where other components tap from. First, is the gas sensor (MQ-9), then the 555Timer, and most importantly, the alarm systems (the four (4) red led and buzzer) and other components as the resistors and capacitors.

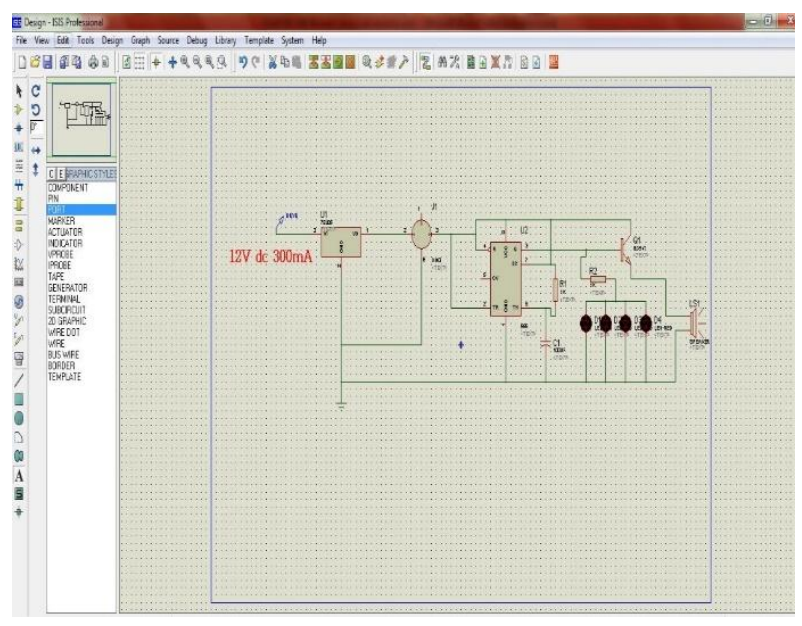

Figure 3a: Circuit diagram for the gas detector with audible alarm system with ISIS Professional

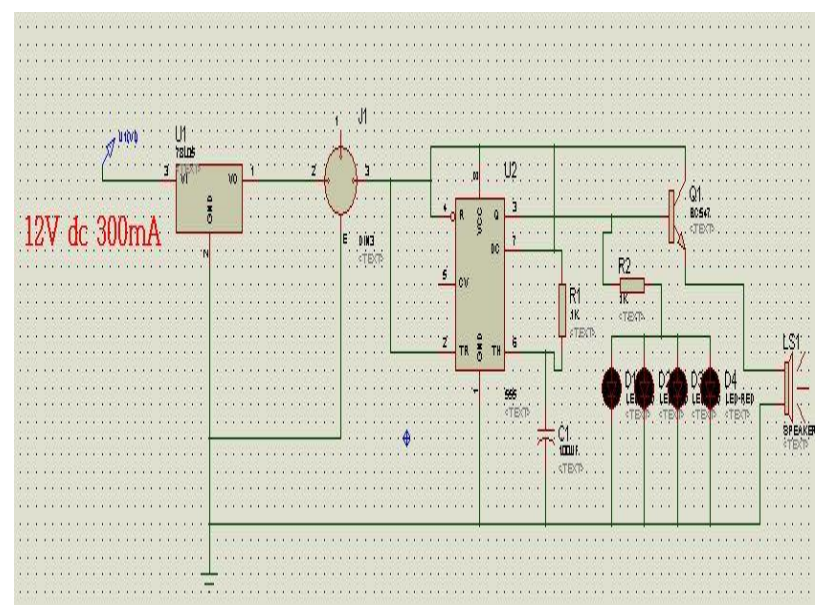

Figure 3b: Close Circuit diagram for the gas detector with audible alarm system.

\subsection{Principle of operation}

The gas detector alarm system is designed with the intention to ensure that the event of gas is intelligently detected, promptly notified and interactively managed. It is built around a timer to accept input from the gas sensor, MQ-9, and activate a buzzer and set of led that alerts in the event of gas. The sensor used is the MQ-9 and from the datasheet, it specializes in gas detection equipment for carbon monoxide and $\mathrm{CH}_{4}$, LPG family and any other relevant industry or car assemblage.

\subsection{Sensor}

For detecting the event of gas which is associated with fire is monitored using a gas sensor.

It advantage is that it has;

- Good sensitivity to $\mathrm{CO} / \mathrm{Combustible} \mathrm{gas}$

- High sensitivity to Methane, Propane and CO

- $\quad$ Long life and low cost

- Simple drive circuit

The enveloped MQ-9 has 6 pins, 4 of which are used to fetch signals, and other 2 for providing heating current. The sensor works with voltages between $5 \mathrm{~V}$ and $12 \mathrm{~V}$ AC or DC. A $5 \mathrm{~V}$ supply voltage was used for this design. Once powered, the output of the sensor is normally HIGH but goes LOW when gas is sensed.

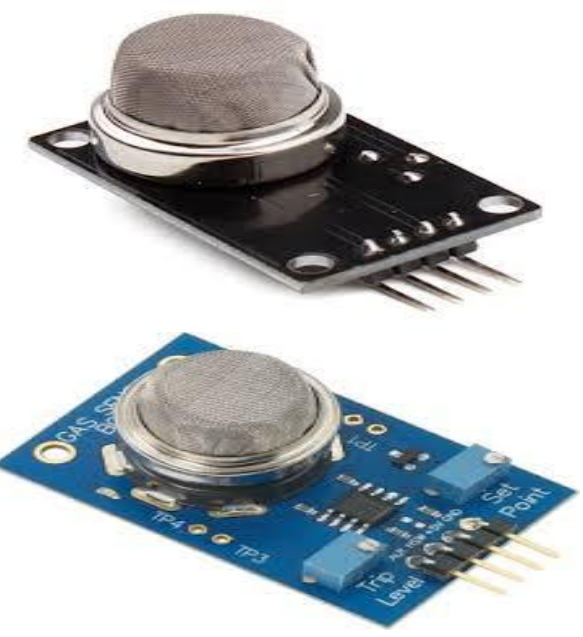

Figure 3c:The MQ-9 gas sensor.

\section{IMPLEMENTATION AND TESTING 4.1 Construction}

The physical realization of the project is very vital. This is where the fantasy of the whole idea meets reality. Here the paper work is transformed into a finished hardware.

\section{Notables on the Design;}

1. Set of pore holes for proper ventilation and proper communication between the circuit and the external environment.

2. When the circuit is $\mathrm{ON}$, a green led comes $\mathrm{ON}$, and red when gas is sensed.

3. A protruded sensor for proper contact in detecting gas.

4. The packaged container fit the size of the circuit 
After carrying out all the paper design and analysis, the idea was implemented, constructed and tested to ensure its working ability.

\subsection{Implementation}

The implementation of the principles on bread board was successful and it met the desired design aim with each stage performing as anticipated.

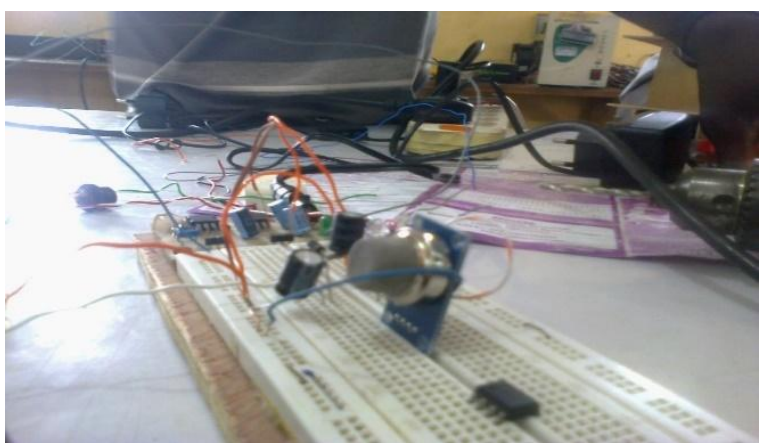

Figure 4a: Solder-less Arrangement

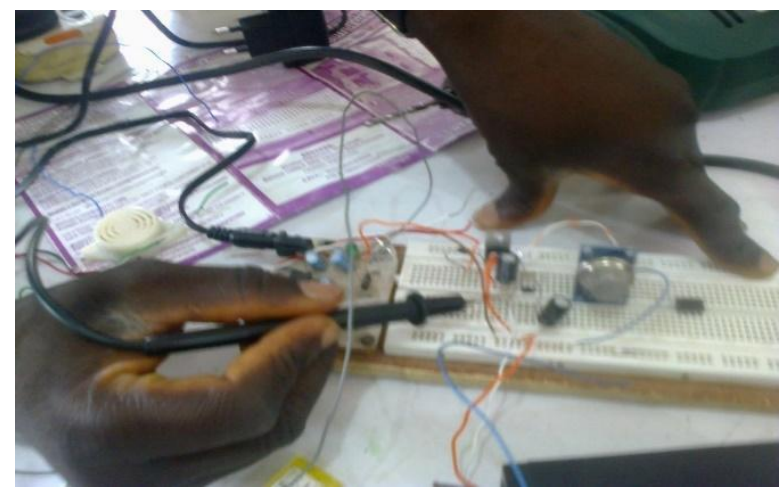

Figure 4b: Powering and Troubleshooting on the Solderless Board

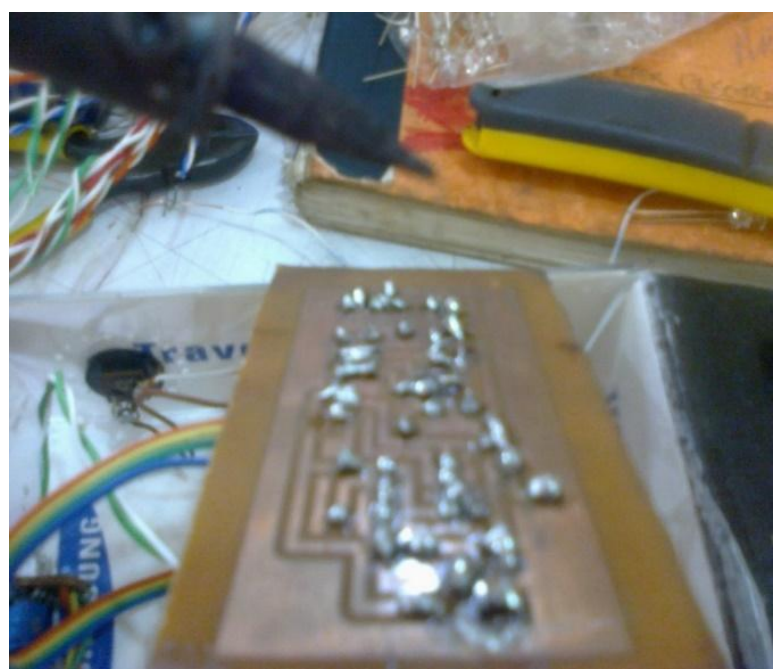

Figure 4c: A components layout on printed circuit board.

\subsection{Casing and Boxing.}

The third phase is the boxing done in a plastic casing. The casing material being plastic was designed with special perforation and vents and also well labelled to give ecstatic value.

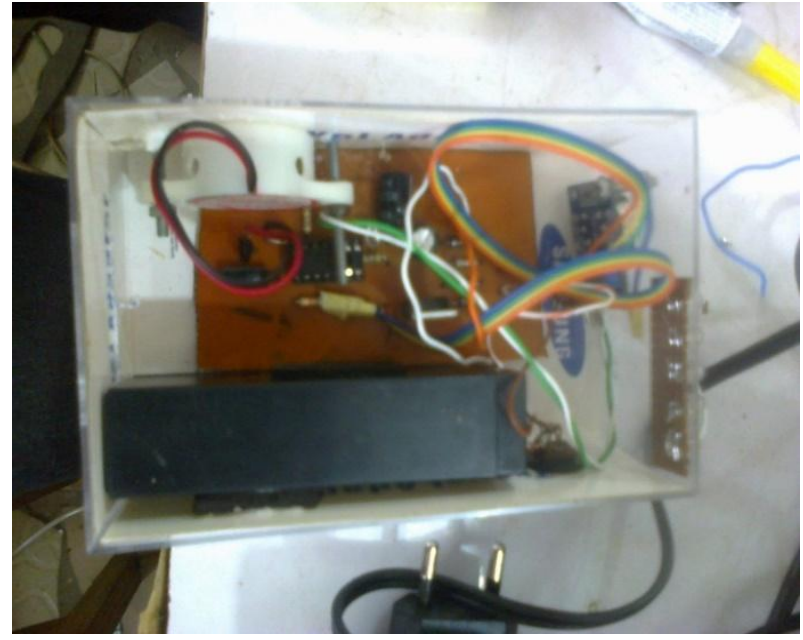

Figure 4d:Circuit Boxing

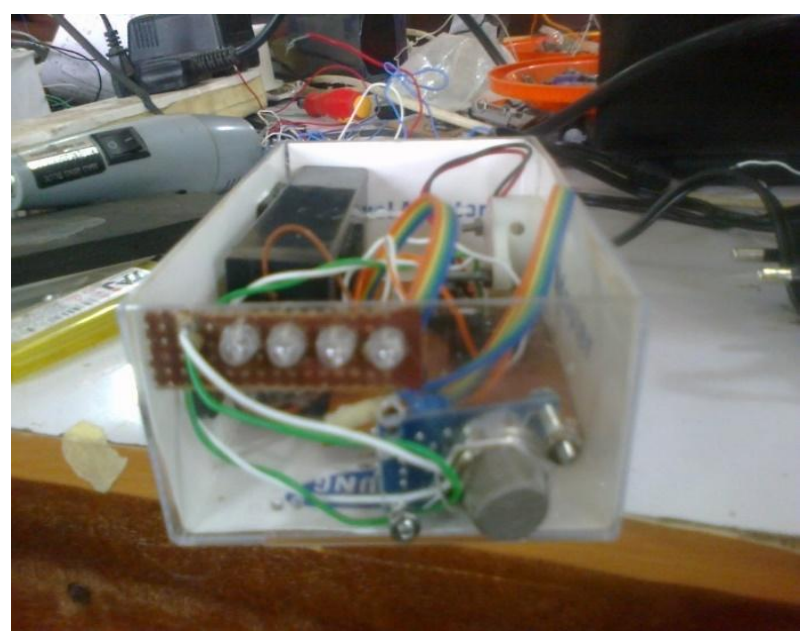

Figure 4e: Circuit Casing

\subsection{Testing}

The testing was done in stages according to the block representation on the breadboard, before soldering of circuit commenced on printed circuit board.

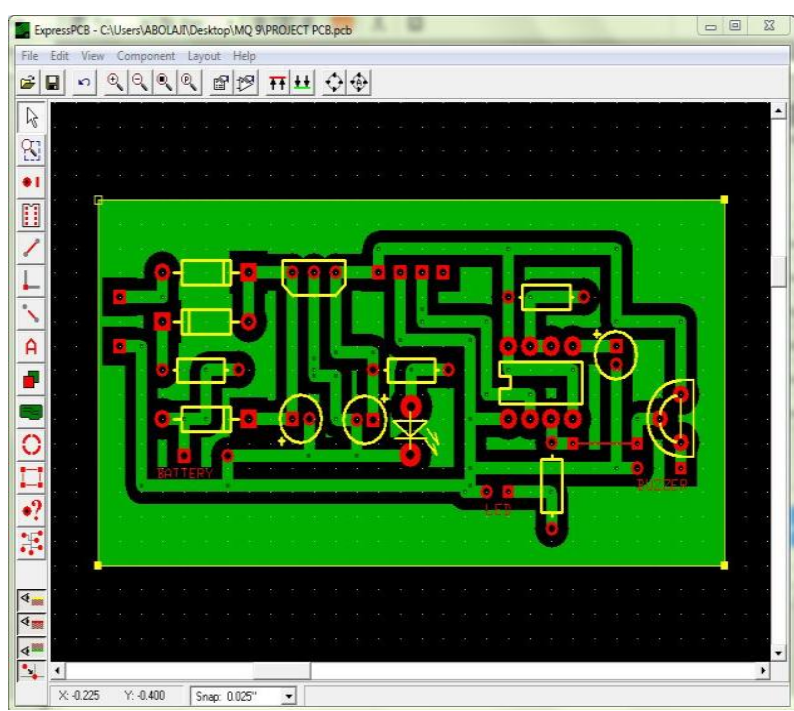

Figure 4f: The PCB layout of the circuit 


\section{CONCLUSIONAND RECOMMENDATION \\ 5.1 Summary of Work.}

From the achievement of this research, the following can be deduced.

(i) The design will find great use in an environment where someone is, or people are deaf and dumb as the combination of the red LEDs glow with intense danger signs.

(ii) In the case of blind occupants, the buzzer alert will offer a means of informing the former of an impending danger.

\subsection{Conclusion}

The gas detector system implemented met certain favourable conditions such as low cost, vast application, design economy, availability of components (locally sourced) and research materials, efficiency, compatibility, portability and also durability. The performance of the project after test, met design specifications. However, the general operation of the system and performance is dependent on the user who is prone to human error such as entering wrong timing. The construction was done in such a way that it makes maintenance and repairs an easy task and affordable for the user should there be any system breakdown.

\subsection{Recommendation.}

Future work can include an integration of other means of sending information to relevant, official authorities like the Fire Service Operators.

\section{REFERENCES}

[1] A Practical Guide to Fire Alarm Systems 2011 Third Edition Central Station Alarm Association 8150 Leesburg Pike Suite 700 Vienna, VA 22182.

[2] A.I.C.E (1999): "American Institute of Chemical Engineers". 95(7): 137.

[3] Bernard Kleane and Russell Sander (2007): "Structural Firefighting", Strategy and Tactics: $1^{\text {st }}$ edition Jones \& Bartlett Learning.

[4] Chen P. and Jiang X. (2008) Design and Implementation of Remote Monitoring System Based on GSM.
Proceedings of IEEE conference on Computational Intelligence and Industrial Application, 2008. PACIIA '08. Pacific-Asia Workshop on 1:678-681.

[5] FULLWIKIPEDIA (2014) [Online] Available from: http://www.thefullwiki.org/Microcontroller

[6] Guylène Proulx 2000. Why Building Occupants Ignore Fire Alarms. Construction Technology Update No. 42 (C) National Research Council of Canada.

[7] Heath, Steve 2003. Embedded systems design. EDN series for design engineers (2 ed.). Newnes. pp. 1112. ISBN 9780750655460.

[8] Mehta V.K (2003): "Principles of Electronics". .Published By S.Chand \& Company Ltd.

[9] Puran G., Bhausaheb S., and Sagar S. (2014) Review on Gas Leak Detection Techniques. International Journal of scientific Engineering and Technology Research. 3(15): 3204-3207.

[10] Ramya V. and Palaniappan B. (2012) Embedded system for Hazardous gas detection and alerting. International Journal of Distributed and parallel systems (IJDPA), 3:287-300

[11] Song L. and Xiong H. (2011) Advances in Computer Science, Environment, Ecoinformatics and Education", Part II: International Conference CSEE: 331

[12] Soundarya T., Anchitaalagammai J.V, Deepa P., and Karthick Kumar S.S. (2014) C-leakage: Cylinder LPG Gas leakage Detection for home safety. IOSR Journal of Electronics and Communication (IOSR-JECE). 9(1):5358

[13] WIKIPEDIA (2014) [Online] Available from: http://en.wikipedia.org/wiki/Microcontroller

[14] WIKIPEDIA (2014) [Online] Available from: http://en.wikipedia.org/wiki/Security

[15] Xie Z. Tan Q. (2006) A Mini Multi-Gas Detection System Based on Infrared Principle, International Journal Mill waves. Pp. 1639-1649. 